\title{
Translation in English and Chinese Idioms from Metonymy
}

\author{
SHAN Xinrong JIA Shaodong \\ Guangzhou College of Applied Science and Technology, Guangzhou City, China
}

Received: May 16, $2021 \quad$ Accepted: July 26, $2021 \quad$ Published: August 30, 2021

To cite this article: SHAN Xinrong \& JIA Shaodong. (2021). Translation in English and Chinese idioms from metonymy. Asia -Pacific Journal of Humanities and Social Sciences, 01: 2, 083-089, DOI: 10.53789/j.1653-0465.2021.0102.009.p

To link to this article: https: //doi.org/10.53789/j.1653-0465.2021.0102.009.p

The research project entitled "The South China Sea 'Geng Lu Book' Research in Translation: Taking Su Deliu and Peng Zhengkai's Manuscripts as Examples" is supported by Guangdong Planning Office of Philosophy and Social Science "Thirteenth Five-Year Plan" Project with No. GD20LMZZY04.

\begin{abstract}
Based on metonymy theory, this paper researches the translation strategies and methods in full, half and zero correspondence idioms in translation. The results show that the full correspondence of English and Chinese idioms focuses on literal translation. Half correspondence should adopt literal and annotation, metonymy translation. Idiom translation involves the translator's subjective intention, understanding and expression, also reflecting on cultural transmission and expression. It is significant to make use of translation teaching and translation practice.
\end{abstract}

Keywords: metonymy; English and Chinese idioms; comparative study

Notes on the contributor: SHAN Xinrong holds a master's degree in Bachelor of Art. She is currently a teacher in Guangzhou College of Applied Science and Technology with academic interest in cognitive linguistics, translation theory and practice. JIA Shaodong holds a degree in Bachelor of Art. He is currently a teacher in Guangzhou College of Applied Science and Technology with academic interest in translation theory and practice.

\section{轉喻視域下的英漢習語翻譯研究}

單新榮 賈紹東

廣州應用科技學院

\begin{abstract}
摘 要: 基於轉喻的認知屬性和轉喻相鄰性所指關系, 提出英漢習語的轉喻翻譯策略。從英漢習語的形式與意義 來看, 英漢習語呈全對應、半對應和零對應關系。研究認為英漢習語的全對應關系側重歸化、直譯翻譯方法; 半對 應關系則應采用直譯+註釋和意譯的翻譯方法; 零對應關系多側重異化、轉譯和意譯的翻譯方法。習語翻譯涉及譯 者的主觀意向性,對習語的理解和表達體現了文化的傳遞和語言的表意方式。本研究對翻譯教學和翻譯實踐具有 借鑒意義。
\end{abstract}


關鍵詞: 轉喻視域; 英漢習語; 翻譯研究

基金項目: 廣東省哲學社會科學“十三五”規劃 2020 年度冷門絕學研究專項課題《南海“更路簿”翻譯研究一一以 蘇德柳和彭正楷抄本為例》階段研究成果之一。

\section{引言}

習語是由固定的詞組和句子所構成的語言表達形式, 漢語稱其為 “熟語”,包括成語、諺語、典故、俗語 等, 習語具有深厚的文化含義。“轉喻主要具有一種指代功能, 它允許我們用一種實體代替另一實體, 同時, 轉喻是一個認知過程, 讓我們通過與其他事件的關系對另一件事件進行概念化理解。” (1) “概念轉喻是在同一 個認知域中源域為目標域提供心理可及的認知操作過程, 源域和目標域之間的關系是或然的, 目標域處於 突顯位置, 源域處於背景化位置, 源域和目標域之間的轉喻關系密切程度在於源域和目標域之間的概念距 離和源域的突顯程度。” (2) “轉喻 ( conceptual) 是一種映現, 是一種 “替代 ( stand-for)” 關系”。点不同的轉喻由 相對突顯 (relative salience) 的認知原則提供理據, 突顯的項目作內容以認知為參照點, 來喚起相鄰的內容, 借助語境, 對對應内容進行識解 (construal)。相對隱喻的研究習語翻譯, 轉喻研究習語翻譯的文獻較少。 䁘於習語的形式與意義差異較大, 借助轉喻理論, 基於隱喻研究的基礎, 本研究從概念轉喻角度對英漢習語 形式與意義進行分析,研究轉喻在習語翻譯方面的運作機製及翻譯策略。

\section{一、轉喻研究}

近年來, 學者們從多角度對習語翻譯進行了研究,例如劉艶芳從順應論的角度探討了新聞報道中不同 文化的碰撞,結合語言、文化和交際三個維度進行轉換,認為“譯者在翻譯過程中不僅要關註語言形式的適 應性選擇轉換, 更要關註雙語文化內涵和交際效果圖的傳遞與闈釋”。 (4) 單偉龍分析了莫言作品中的習語英 譯本中的翻譯, 研究了譯者翻譯習語使用直譯、意譯的翻譯方法。 ${ }^{5}$ 邱能生根據 Nida 的文化理論、Venuti 異 化、歸化分類,認為 “習語的翻譯應側重異化的翻譯方法”。對習語的轉喻翻譯,國內學者肖坤學基於認知語 言學的語言觀與轉喻構建的認知特點, 提出了以轉喻構建為依據、以意義為參照的轉喻翻譯思想,認為“從 隱喻研究角度更在多數, 但是轉喻如同隱喻一樣, 是人們認知事物的一種方式, 伴隨著語言左右。” 7 譚業升 㘓釋了轉喻圖式--例示級階的翻譯轉換、翻譯變體的創造性翻譯的理念,並且提出 “在翻譯過程中以語境為 基礎並受規約限製的轉喻認知方式。” ${ }^{8}$ 盧衛中以認知的概念轉喻理論為指導探討了轉喻翻譯的認知基礎與 策略,運用認知語言學理論解決轉喻翻譯的實際問題。

認知語言學家王寅提出 “翻譯是一種認知活動, 是以現實體驗為背景的認知主體所參與的多重互動作 用為認知基礎的”、“翻譯具有體驗性”。回體驗性構成了不同語言之間具有互譯性的認知基礎。翻譯的體驗 性一方面表現為原文本是作者對現實世界的體驗, 另一方面為譯者對原文本的理解和推理。奈達認為“翻譯 的目的在於把源語的全部信息在譯語中再現並取得最大限度的等值效果” ${ }^{\mathbb{1 1}}$, 因此翻譯中的等值是經驗結構 的相似性,換言之, 翻譯某種意義上要求概念對等。翻譯被認為是一種轉喻思維的體現,轉喻翻譯是一種主 體意識活動。意向性是人的意識的一項核心內容, 可體現為意識活動的一種工具, 是意識觀照 ( construe) 事物事件事態時所展現出的一種體現利己的取舍傾向。

從“中國知網” 文獻中的主題輸人 “轉喻” 和“習語翻譯” 可得到文獻總數:6 篇; 檢索條件: (主題 = 轉 喻 或者 題名 $=$ 轉喻 或者 $\mathrm{v} \_$subject $=$中英文擴展 (轉喻, 中英文對照) 或者 $\mathrm{title}=$ 中英文擴展 (轉喻, 中英 文對照 $)$ 並且 $\left(\right.$ 主題 $=$ 習語翻譯 或者 題名 $=$ 習語翻譯 或者 $\mathrm{v} \_$subject $=$中英文擴展 $($習語翻譯, 中英文對 照) 或者 title = 中英文擴展 (習語翻譯, 中英文對照) ) 我們發現 2010-2019 年間有關“轉喻翻譯” 和“習 
語”的發文量有 14 篇,平均每年發文一篇。在發文中, 以“英語習語”和“習語翻譯” 文獻數各為 2 篇, 以“翻 譯策略”、“英語文化背景”、“英語表達”、“英國人”、“英語國家文化”、“動物詞”等都為 1 篇, 相對於“轉喻” 和“翻譯”的文獻數 ( 299 篇) 來說, 習語翻譯研究需進一步深人。

Smith 最早強調了習語的基本特征,認為“習語的意義不是它的組成詞的意義的總和,對習語的研究提 供了有價值的參考。” ${ }^{1}$ 美國著名翻譯理論家尤金 - 奈達認為翻譯是再現原義的信息, 而不是保留原文的結 構; 翻譯對等不是同一, 没有完全的對等, 意義是譯者優先考慮的因素; 翻譯的過程中, 不但要考慮譯出語和 譯人語的差異, 更要考慮作為文化載體的兩種語言所產生的文化差異。習語作為語言的精華及文化的載 體, 在各種交際場所, 習語使用的使用頻率更高。認知語言學為習語的理解和翻譯提供了新的研究途徑。

\section{二、英漢習語轉喻形式與意義對比分析}

語言符號是形式和意義的統一體,習語也不例外。習語的形式即習語字面義所傳達的信息作為認知參 照為隱含的意義提供心理通道, 實際的含義需依賴人們的思維方式進行推理才能獲得。習語的意義具有一 定的文化背景,其意義的不確定性通過相鄰、相近或 “部分激活整體” 的轉喻思維來推理。因此,在翻譯過程 中,對源文本的解讀體現了相鄰、相近和“部分代整體”、“整體帶部分”的轉喻思維。英漢兩種語言分屬不同 的文化, 從對比的角度來看, 英漢習語可分為相互對應,半對應和非對應的英漢習語, 具體例示如下:

\begin{tabular}{|c|c|c|c|}
\hline 序號 & 源語 & 目的語 & 對應關系 \\
\hline 1 & He who rides a tiger is afraid to dismount & 騎虎難下 & \multirow{2}{*}{ 全對應關系 } \\
\hline 2 & 好馬無劣色 & A good horse cannot be of a bad colour & \\
\hline 3 & the apple of one's eye & 掌上明珠 & \multirow{2}{*}{ 半對應關系 } \\
\hline 4 & 膽小如鼠 & as timid as a hare & \\
\hline 5 & to draw one's blood & 惹人生氣 & \multirow{3}{*}{ 零對應關系 } \\
\hline 6 & 依賴某人 & to hang on sb.'s sleeve & \\
\hline 7 & 四面楚歌 & to be besieged on all sides & \\
\hline
\end{tabular}

例 1 和例 2 中英語習語或諺語在漢語中都有對應的動物, 而且動物意象相近, 都有與之相對應的漢語習 語或諺語。例 1 中的 “tiger” 翻譯這類英語習語時, 形式和意義相對應的漢語習語是最佳譯法。漢語也有一 些習語, 與英語的一些習語相對應。例 3 和例 4 呈半對應關系, 通過部分代替整體的轉喻思維對應在英漢習 語占習語中的大部分。半對應的英漢習語通常是轉喻意義相同, 但喻體形象迥異。譯者須對源語習語意象 加以轉換, 產生聯想, 用合適的目的語將其譯出。例 5 和例 6 中的英語習語涉及獨特的西方文化意象, 染上 了獨特的西方文化色彩, 只有采用意譯法處理, 才能為目標語 (譯文) 所理解。例 7 這類習語是漢語歷史上 留傳下來的典故和成語, 字面翻譯無法為英文讀者所接受; 如果加上一長串解釋性文字, 就失去了成語精粹 的特點。最好的辦法是避開其文化背景, 譯出隱性的含義。翻譯過程中, 譯者的目標域的取舍受到譯者的 意向性, 目的語接受者的文化喜好、理解程度等因素的製約, 導致習語翻譯時產生不同的翻譯策略。

\section{三、轉喻翻譯的機製}

轉喻是一種認知操作方式, 在翻譯中, 譯者的主體性活動得到充分發揮, 英漢思維方式和表達方式也有 
Asia-Pacific Journal of Humanities and Social Sciences

差異。漢民族原始社會以母系社會為主,生活具有典型的農耕特色, 習語中“牛馬年,好耕田”,用“耕田” 來 表達“農耕生活”, 實現事件要素之間的轉換; 英語習語則多使用功能轉換的轉喻詞.英漢民族思維重視膚色 與種族或階級差異,如“red tape (官僚作風)”。英漢民族中間經歷了以體驗為基礎的復雜過程。劉宓慶認 為翻譯首先是對語符形式的意義構建,因為“所謂翻譯的本質, 就是意義的語際轉換”。譯者對源語文本進 行解讀, 在理解的基礎上形成概念和意義,建構認知信息, 然後在目的語中將該認知信息用語言形式表征出 來。意義的建構是一個推理的過程。原文本的語言符號所編碼的信息作為認知參照點為隱含的意義提供 心理通道, “顯性的語言編碼只是讓我們到達了一個正確的鄰近地區, 但要找到確切的位置還需其他方法”。 也就是說, 語言符號僅僅具有產生某種意義的潛勢, 具體的意義還要依賴人們的思維方式進行推理才能獲 得。這種意義的不確定性通過語境的激活 到達目標的心理通道。

譯者對源文本進行解構, 在頭腦中形成了概念和意義, 根據表達習慣, 在源語中表達整體意義的詞語在 目的語中會尋找和挑選部分意義來替代,產生 “部分替代整體”、“整體替代部分” 和“部分替代部分” 等關 系。在翻譯過程中, 作為認知機製的轉喻也是一種翻譯策略。轉喻作為翻譯策略主要體現在以下方面:

\section{（一）“部分替代整體”的轉喻機製}

源文中没有使用轉喻思維,但在翻譯過程中采用轉喻思維機製, 從而使譯文更加生動形象。

例 8 : 他愛財如命, 可是為了維持事情, 不得不狠了心。(老舍,《駱駝祥子》)

譯文: Though it was like spending his life's blood, he gritted his teeth in order to keep the job.

譯文存在著用名詞短語“his life’s blood”代替“生命” 的跨語言轉喻用法,體現的是由組成部分轉指整個 人的生命。就翻譯而言,譯文“his life” 與源文“愛財如命”之間構成了“部分替代整體”的轉喻關系。

\section{（二）“部分替代部分”的轉喻機製}

“部分代部分” 對於同一個目標概念, 兩種語言可能會選取實體的不同部分或屬性來表征該事物。因為 鄰近關系在不同語言中的凸顯程度是不一樣,因此在源語中用事物的某一屬性或特征來通達該事物, 而在 目的語中可能選取的是事物的另一屬性或特征,但這些屬性或特征處於同一個認知框架中,構成“部分代部 分” 的轉喻關系, 例如:

例 9: The dignity of the snow-capped mountain is lost in distinctness but the joy of the tourist is to recognize the traveller on the top. The desire to see, for the sake of seeing, is, with the mass, alone the one to be gratified, hence the delight in detail. Nature and Art (James Whistler)

譯文: 白雪皚皚的高山因其清晰可見而失去它的尊嚴, 但旅遊者卻因能夠看見站在山頂上的遊人而喜 形於色。對於大多數人,單是為了要看見而要看見的願望需要得到滿足而已,因此,他們僅以能看見細節 為快。

譯文中“snow-capped”用事物的組成部分譯人事物的屬性, 部分代替部分。在源語中用山的頂部高的 特征來表達雪的覆蓋, 目的語中選取的是事物的屬性 “白雪皚皚” 來翻譯。英語語言註意白的自然特性, 漢 語關註事物的結果,構成部分替代部分的轉喻翻譯。

\section{（三）“整體替代部分”的轉喻機製}

在翻譯過程中, 源語中的整體概念在目的語中可能用部分概念來表達, 或者源語中的事物在目的語中 用其特征或屬性來表達。換言之, 在為目標概念提供心理可及的過程中, 源語中的概念和目的語中的概念 構成整體和部分的轉喻關系。

例 10 :輕聲細語

譯文: say in the silkiest voice 
漢語“輕聲細語”指說話時聲音很小很細,一般用來形容女子說話,而譯文則借“voice”轉指“聲音”, 就 譯人語與源語的關系而言,兩者之間構成了“聲音代話語”的跨語言轉喻關系。

為了保持與源文一致的心理可及過程, 轉喻翻譯必須盡量保留源文的轉喻特征, 這包含以下兩方面的 含義: 首先, 譯文要盡可能讓譯文讀者獲得與源文讀者相同的心理反應。換言之, 在翻譯的過程中, 譯文應 盡量保留源概念為目標概念提供心理可及的轉喻思維過程。這種心理可及的過程是意義層面的。因此, 在 不同的語言中, 表達目標概念的源概念的語言表達形式可能不一樣,但認知過程是一致的。其次,譯文要盡 可能再現轉喻的修辭功能, 維持原文的形式美和意蘊美。在使用轉喻的過程中, 為達到譯文的優美, 必須註 重修辭效果。轉喻通常是以凸顯的或具體的事物來為不凸顯的或抽象事物提供心理橋梁,把兩種表面上關 聯不大的對象聯系起來, 引起讀者的聯想、思考和感悟, 從而獲得語言的美感。同時, 轉喻通過簡單的措辭 來傳達復雜的意義, 以達到認知和表達的經濟性。因此, 轉喻翻譯除了保持信息的忠實與文字的通順外, 譯 文還要實現原文修辭效果的對等再現,讓譯文讀者能夠欣賞或領略到原文轉喻的風采。

\section{四、習語翻譯的策略}

認知語言學認為語言是互動體驗與認知加工的產物。由於人類具有相同的生理結構, 不同民族對客觀 世界的體驗與認知在很大程度上具有相似性。然而, 由於不同民族所處的自然環境、歷史文化與風俗習慣 不同, 不同民族的互動體驗、認知加工與語言表達也存在明顯的差異。從形式與意義維面來看,英語與漢語 中習語呈全對應、半對應和零對應關系。針對英漢習語的翻譯, 譯者可視具體情況分別采取直譯、意譯、轉 譯等具體的翻譯策略(如下圖所示)。

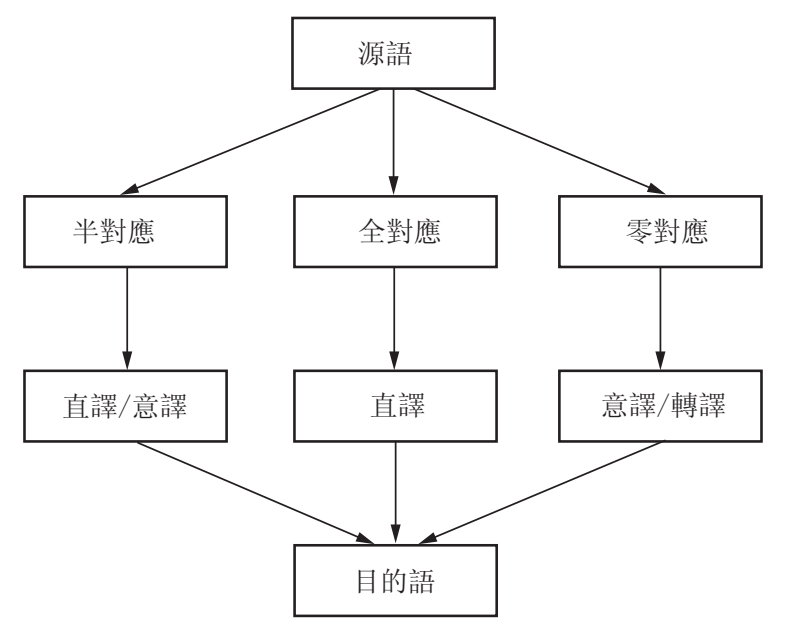

\section{（一）直譯}

直譯是源語的意義在目的語中的再現,源語的轉喻和表達手法在目的語中也會出現。英語的習語在形 式和意義與漢語的形式和意義全對應或半對應常采用直意。

例 11 : 王夫人聽了, 又好笑, 又好惱,說道: “你又發了呆氣了, 混說的是什麼? 大凡做了女孩兒, 終久是 要出門子的, 嫁到人家去, 娘家那裏顧得? 也只好看他自己的命運, 碰得好就好, 碰得不好也就没法兒。你 難道没聽見人說“嫁雞隨雞, 嫁狗隨狗”, 那裏個個都象你大姐姐做娘娘呢? ......” (《紅樓夢》第八十一回)

譯文: Both amused and exasperated, his mother exclaimed, “There you go again-talking nonsense! Sooner or later a girl has to leave home, and once she's married off what can her mother's family do for her? If she happens to get a good husband, fine; if not, there's no help for it - that's fate. Surely you know the saying, "Marry a cock and follow the cock; marry a dog and follow the dog"? How can every girl be like your eldest 
sister, chosen as an Imperial Consort? ..."

習語“Marry a cock and follow the cock; marry a dog and follow the dog”中映射漢民族女性在婚姻中的 依附。這句俗語是從"嫁稀隨稀, 嫁叟隨叟”諧音訛化而來的。“稀”為少年, “叟”為老者,古人的婚姻只能 聽憑父母安排, 兩人甚至在結婚前都不知道對方是老是少, 是美是醜。對對方的印象僅能從父母與媒人的 話中想象, 所以等看到對方的時候, 無論是好是壞都已成定局, 只能認命了。譯者選擇直譯便於理解, 同時 也存在著轉喻思維方式。

\section{（二）直譯+註釋}

源文中的轉喻喻體蓝含豐富的文化內涵, 包含特有的生活習慣、民俗風情、典故、傳說、歷史事件、人物、 政治、宗教等,在另一種文化中用對等的喻體進行翻譯時,往往無法再現原文的文化信息。為了準確表達原 文的意義,讓譯語讀者獲得同樣的認知反應,譯者可以采用“直譯 + 釋義”相結合的翻譯方法,對其文化内涵 進行解釋。

例 $12: \mathrm{He}$ is like a thoroughbred horse, satisfying to the trained eye, docile to the light touch, and coursing in most wonderful unison with you through the open world. (George Santayana, The Weather in His Soul)

譯文: 何況他就像是一匹英國純種馬, 在內行人看來無可挑剔, 輕輕一拍就能領會你的意圖, 載著你穿 越空曠的原野,和你完全融為一體。

在翻譯上有限度地改變原文連續用地使用轉喻進行翻譯, “ satisfying to the trained eye, docile to the light touch, and coursing in most wonderful unison”保持原文意思的連續,全段文字產生統一中有變化的審美 情趣。

\section{（三）轉譯}

由於各民族在社會環境、歷史傳統、宗教信仰等方面的不同,在與客觀世界的互相作用中獲得的經驗會 存在一些差異。這種社會文化的差異也同樣會體現在包括轉喻在內的語言表達形式中。在這種情況下, 原 文中用來激活目標概念的源概念跟譯文中的源概念不一致,但體現了同樣的認知方式。通常情況下不能把 原文中的喻體移植到目的語中, 而是采用目的語中對應的喻體, 對原文中的轉喻進行轉譯, 使轉喻的信息在 目的語讀者的認知語境中易於接受,從而實現翻譯等值。

例 13 : 肖英受到十足地傷害, 人們幾乎一致認為她這是傍大款。

譯文:It is Xiaoying who suffers completely, because almost all the people think she has found a sugar daddy as her husband.

上句是“傍大款” 在原文中所要表達的是“年輕女子嫁給有錢人” 的意思,含貶義。這個漢語習語所描述 的社會現象並不是中國特有,這樣一種社會現象和轉喻表達在漢語和英語中都有。翻譯所采用的策略便是 轉換喻體, 即找到英語讀者所熟悉的喻體來表達同樣的含義。在這個例子中 “found a sugar daddy” 便是英語 讀者所熟悉的喻體,運用這個轉喻能完全表達出原文的含義,並保留了原文的語言特色。

\section{（四）意譯}

當在目的語中找不到與源文一致或對等的源概念來激活目標概念時,通常采用歸化+意譯的方法,即在 理解詞語表層結構的基礎上,用目的語的習慣表達方式把原文中轉喻的目標概念表現出來, 以達到交流的 目的。

例 14 : 小丁在男女的問題上已經可以算是閲盡人間春色了,故而有點修成正果的味道,篤誠篤意地認為 還是一夫一妻的方式最佳, 既人道又天道, 老天是絕不會用艾滋病來騷擾恩愛夫妻的。

譯文:As to sex, Xiao Ding has seen all kinds of beauties, therefore, he has a thorough understanding, and 
sincerely think that monogamy is the best. It is both humane and natural.Loving couples will never be harmed by AIDS.

在這個例句中“閱盡人間春色”這個漢語習語也是有較深的隱喻含義, 指 “經歷過數量眾多的美貌女 子”,屬於漢語中耳熟能詳的表達。但是對於英語讀者來說, “the beautiful scene of spring” 無法和“美女” 聯 系起來,所以這個習語的翻譯舍棄了“人間春色”這個喻體,而直接意譯為“all kinds of beauties”。

譯者在處理習語的轉喻有不同的選擇, 在目的語中有源語的的對應時, 可采用直接翻譯的策略; 若没有 對應的翻譯時,譯者選擇間接翻譯的策略。

\section{結語}

轉喻在習語中使用非常廣泛, 而且形式多樣。轉喻是兩個概念實體可及的心理基礎, 借助鄰近關系實 現不同語際的表達。在翻譯的過程中, 源語表達與目標語的表達出現部分與整體、部分與部分、整體與部分 的不一致, 導致譯者在不同語言的轉換中選取不同的語言載體表達相同的意義。換言之, 對於源語中的心 理可及過程, 譯文可能選取不同的實體來激活目標。在翻譯中, 采用直譯、直譯+釋義和轉譯的的翻譯策略 和方法, 達到 “達” 和 “雅” 的的境界。從宏觀層面研究了概念轉喻在整個翻譯過程中的作用, 認為翻譯是具 有轉喻性的認知活動, 翻譯過程中對文本的理解和表達都體現了轉喻認知語用機製。同時, 轉喻本身也是 一種翻譯策略。通過翻譯, 挖掘深厚的文化意義,對中國文化走出去,增加文化自信,具有一定的意義。

\section{注䆁:}

Lakoff, G, M. \& Johnson. (1980). Metaphors we live by. Chicago: The University of Chicago Press.

Panther, K, U. \& Thornburg, L. (2006). Metonymy and the way we speak. In Benczes R. \& S. Csábi (Eds), The metaphors of sixty: Papers presented on the occasion of the 60 th birthday of Zoltán Kovecses. Budapest: Etvs Loránd University.

Lakoff, G. \& M. Turner. (1989). More than cool reason: A field guide to poetic metaphor. Chicago: The University of Chicago Press. Nida, E, A. (1993). Language, culture and translation. Shanghai: Shanghai Foreign Languages Education Press.

Smith, L. P. (1979). Words and idioms. London: Constable.

劉豐芳: 《從翻譯適應選擇論看新聞報道中隱喻習事的翻譯》,《上海翻譯》2009 年第 4 期。

單偉龍:《基於語料庫的葛浩文習語翻譯研究-一以《紅高梁家族》和《變》為個案》,《外語電化教學》2019年第 2 期。

邱能生, 邱曉琴: 《文化差異背景下英漢習語翻譯的異化和歸化處理探微》《上海翻譯》, 2019 年第 1 期。

肖坤學: 《以認知理據分析為基礎的轉喻翻譯》,《中山大學學報論叢》2006 年第 8 期,第 216-219 頁。

譚業升: 《轉喻的圖示一例示與翻譯的認知路徑》, 《外語教學與研究》2010 年第 6 期,第 465-467 頁。

盧衛中:《轉喻的理解與翻譯》, 《中國翻譯》2011 年第 2 期, 第 64-67頁。

王寅:《認知語言學的翻譯觀》,《中國翻譯》2015 年第 5 期, 第 19-20 頁。

(Editor: Lucy) 